University of Montana

ScholarWorks at University of Montana

Integrative Physiology and Athletic Training

Faculty Publications

Integrative Physiology and Athletic Training

$6-2010$

\title{
Relationship Between Muscle Strength, Power and Stiffness and Running Economy in Trained Male Runners
}

Charles Dumke

University of Montana - Missoula, charles.dumke@umontana.edu

Christopher M. Pfaffenroth

Jeffrey M. McBride

Grant O. McCauley

Follow this and additional works at: https://scholarworks.umt.edu/hhp_pubs

Part of the Medicine and Health Sciences Commons

Let us know how access to this document benefits you.

\section{Recommended Citation}

Dumke, Charles; Pfaffenroth, Christopher M.; McBride, Jeffrey M.; and McCauley, Grant O., "Relationship Between Muscle Strength, Power and Stiffness and Running Economy in Trained Male Runners" (2010). Integrative Physiology and Athletic Training Faculty Publications. 8.

https://scholarworks.umt.edu/hhp_pubs/8

This Article is brought to you for free and open access by the Integrative Physiology and Athletic Training at ScholarWorks at University of Montana. It has been accepted for inclusion in Integrative Physiology and Athletic Training Faculty Publications by an authorized administrator of ScholarWorks at University of Montana. For more information, please contact scholarworks@mso.umt.edu. 


\title{
Relationship Between Muscle Strength, Power and Stiffness and Running Economy in Trained Male Runners
}

\author{
Charles L. Dumke, Christopher M. Pfaffenroth, \\ Jeffrey M. McBride, and Grant O. McCauley
}

\begin{abstract}
Purpose: In this study, a comparison was made between muscle strength, power and muscle and tendon ( $\mathrm{k}_{\mathrm{m}}$ and $\mathrm{k}_{\mathrm{t}}$ respectively) stiffness of the triceps surae muscle group and running economy (RE) in trained male runners. Methods: Twelve welltrained male runners (age $=21 \pm 2.7 \mathrm{y}$, height $=178.1 \pm 7.1 \mathrm{~cm}$, body mass $=$ $66.7 \pm 3.2 \mathrm{~kg}, \mathrm{VO}_{2} \max =68.3 \pm 4.3 \mathrm{~mL} \cdot \mathrm{kg}^{-1} \cdot \mathrm{min}^{-1}, 5000-\mathrm{m}$ time $=15: 04 \mathrm{~min}: \mathrm{s}$ ) underwent passive stiffness testing using a free oscillation method. Muscle strength was determined via a maximal isometric squat test and power determined via a maximal countermovement jump (CMJ). On a separate day, subjects performed an incremental treadmill test and their $\mathrm{RE}$, lactate threshold, and $\mathrm{VO}_{2}$ max were determined. Fingertip blood lactate was determined at the end of each 3-min stage. Lactate threshold was defined as a nonlinear increase in lactate accumulation. Results: A statistically significant correlation was found between $\mathrm{k}_{\mathrm{m}}$ and $\mathrm{VO}_{2}$ at stage $6(r=-0.69, P=.01)$. In addition, statistically significant correlations were observed between $\mathrm{CMJ}$ peak force production and $\mathrm{VO}_{2}$ at stage $2(r=.66, P=$ $.02)$, stage $3(r=.70, P=.01)$, and stage $4(r=.58, P=.04)$. No other statistically significant correlations were observed. Conclusion: These data suggest that greater muscle stiffness and less power are associated with greater RE. Future study in this area should focus on determining the mechanisms behind this relationship and how to best apply them to a running population through training techniques.
\end{abstract}

Keywords: free oscillation, lactate threshold, endurance performance, efficiency

Running economy (RE) is commonly defined as the relationship between oxygen consumption $\left(\mathrm{VO}_{2}\right)$ and running velocity. ${ }^{1}$ Therefore, a lower $\mathrm{VO}_{2}$ at a given velocity would indicate greater running economy. Although a high maximal oxygen consumption $\left(\mathrm{VO}_{2} \max \right)$ is typically associated with running performance, research suggests that RE may be of greater importance to endurance performance. ${ }^{2,3}$ If this is the case, then more focus should be given to understanding the components of $\mathrm{RE}$, which could lead to better training modalities to increase performance.

Charles L. Dumke is with the Department of Health and Human Performance, University of Montana, Missoula, Montana. Pfaffenroth, McBride, and McCauley are with the Neuromuscular Laboratory, Appalachian State University, Boone, NC. 
Several factors have been shown to improve running economy, including a variety of training approaches from interval and altitude training to strength training. ${ }^{4-10}$ The relationship between strength training and RE is not a new concept. In fact, several research investigations have shown that strength training (both explosive and high resistance) can improve RE in untrained and trained subjects. ${ }^{5,7-12}$ Paavolainen et al ${ }^{5}$ found that explosive strength training improved not only 5-km running performance, but also RE and muscle power. This result was confirmed by several additional studies in which RE was improved following a short-term implementation of a plyometric or explosive strength training regimen. ${ }^{7,9,12-14}$ In general, RE appears to be trainable; however, the key factors in that result in improved RE with training remain elusive.

Recently, there is increased interest in muscle and tendon stiffness and how it relates to strength and power production in many different modalities. Wilson et $\mathrm{al}^{15}$ demonstrated that muscle stiffness related positively to power production during the bench press. Since improving strength and power was shown in previous research to improve RE and performance, it has been proposed that it may occur through changes in muscle $\left(\mathrm{k}_{\mathrm{m}}\right)$ and tendon $\left(\mathrm{k}_{\mathrm{t}}\right)$ stiffness. ${ }^{10,16-18}$ These parameters have been examined previously using a free oscillation technique. Both muscle and tendon properties may be important in this transfer of energy during human locomotion. Stored energy in these springs (muscle and tendon) could conceivably reduce muscle activation and spare energy expenditure, thus improving RE. Yet it remains unclear the magnitude of muscle or tendon stiffness contribution to $\mathrm{RE}$, or which of the two is more critical. Kyrolainen et $\mathrm{al}^{19}$ found that there was an association between enhanced RE and myosin heavy chain and titin isoforms in well-trained middle distance runners. Titin in particular is a protein that may affect muscle stiffness properties, although changes in titin isoforms with training have not been investigated. Overall leg and musculotendinous unit stiffness may be considered important components of RE. ${ }^{10,13,20-23}$ In one investigation it was demonstrated that improvements were made in 3000-m time-trial performance, $\mathrm{RE}$, and musculotendinous stiffness with no corresponding changes in $\mathrm{VO}_{2} \max$ following $6 \mathrm{wk}$ of plyometric training. ${ }^{10}$ Although this study did show an increase in performance and RE, the subjects were not competitive runners. In fact, very few studies have examined the relationship between RE, muscle and tendon stiffness and performance in a group of well-trained athletes.

The aim of this study was to explore the relationship between passive muscle and tendon stiffness, muscle strength and power, and RE in a well-trained group of runners. We hypothesize that increased muscle and tendon stiffness will relate to greater lower body strength and power and improved RE.

\section{Methods}

\section{Subjects}

The subjects $(\mathrm{n}=12)$ that volunteered for this study were well-trained athletes (age = $21.0 \pm 2.7 \mathrm{y}$, height $=178.1 \pm 7.1 \mathrm{~cm}$, weight $=66.2 \pm 5.8 \mathrm{~kg}, \mathrm{VO}_{2} \max =68.3 \pm 4.3$ $\mathrm{mL} \cdot \mathrm{kg}^{-1} \cdot \mathrm{min}^{-1}$, training volume $=96.8 \pm 23.6 \mathrm{~km} \cdot \mathrm{wk}^{-1}$, years competing $=7.9 \pm 3.1$ ), and individual performance records are presented in Table 1. None of the subjects had any current injuries during the experimental period. All subjects provided consent for the study in accordance with the Appalachian State University Internal Review Board. 
Table 1 Correlations between time for distance run (s) and total years of running experience. All correlations are significant $(P \leq .05)$.

\begin{tabular}{lcc}
\hline Distance & Mean \pm SD $(\mathbf{s})$ & Significance $(\boldsymbol{P} \leq .05)$ \\
\hline $3000 \mathrm{~m}$ & $516.2 \pm 29.24$ & $r=-0.77, P=.004$ \\
$5000 \mathrm{~m}$ & $904.5 \pm 53.31$ & $r=-0.85, P=.002$ \\
$8000 \mathrm{~m}$ & $1503.9 \pm 86.39$ & $r=-0.83, P=.002$ \\
$10,000 \mathrm{~m}$ & $1950.38 \pm 96.00$ & $r=-0.74, P=.03$ \\
\hline
\end{tabular}

\section{Design}

This was a cross-sectional study of well-trained runners relating running economy to muscle and tendon stiffness. Testing occurred on consecutive days, with muscular testing on Day 1 (muscle and tendon stiffness, power, and strength) and metabolic testing on Day 2 ( $\mathrm{VO}_{2} \max$, lactate threshold, running economy, ventilation and heart rate, sit and reach, body composition). The tests were conducted on separate but concurrent days to prevent the tests from affecting one another. Subjects were tested in the preparatory phase before the new competitive season.

\section{Methodology}

Muscle and Tendon Stiffness Measurements. On Day 1 muscle and tendon stiffness was measured using a previously established reliable free oscillation technique. ${ }^{24-26}$ This method is the most valid means of measuring both passive muscle and tendon stiffness in the triceps surae muscle group concurrently. Briefly, subjects first performed a maximal isometric plantar flexion on a force plate (Iso. PF) with their knees braced. Subjects sat on a chair with knees and ankles at $90^{\circ}$ with the balls of the foot on the force plate. For measurement of maximal isometric force, subjects sat with knees and ankles at a $90^{\circ}$ angle with an oscillation device placed on their knees. Subjects were then loaded with weights ranging from $5 \%$ to $40 \%$ (in $5 \%$ increments) of their maximal isometric plantar flexion force in succession. Each load was tapped with a $10-\mathrm{kg}$ weight to measure the oscillation of the lower leg through the force plate. Tendon stiffness $\left(\mathrm{k}_{\mathrm{t}}\right)$ and muscle stiffness $\left(\mathrm{k}_{\mathrm{m}}\right)$ were then determined using the dampened force oscillation pattern and the equation for motion of a dampened spring model (Figure 1). ${ }^{24-26}$ Reliability of $\mathrm{k}$ $\left(\mathrm{kN} \cdot \mathrm{min}^{-1}\right)$ between trials was $R^{2}=.995$.

Power Measurements. Subjects performed countermovement jumps (CMJs) and static jumps (SJs) on a force plate (AMTI, BP6001200, Watertown, MA, USA) on Day 1. The CMJ was performed with a stretch-shortening cycle and the SJ involved only the concentric phase starting from a squatted position. Subjects were permitted a minimum of two trials, and a 2-min rest period was provided between trials. During the CMJ, peak force, peak power, peak velocity, and jump height were determined. Subjects were required to hold a plastic bar across their shoulders and were instructed to keep constant downward pressure on the bar throughout the jump so that the bar would not move independently of the body. 


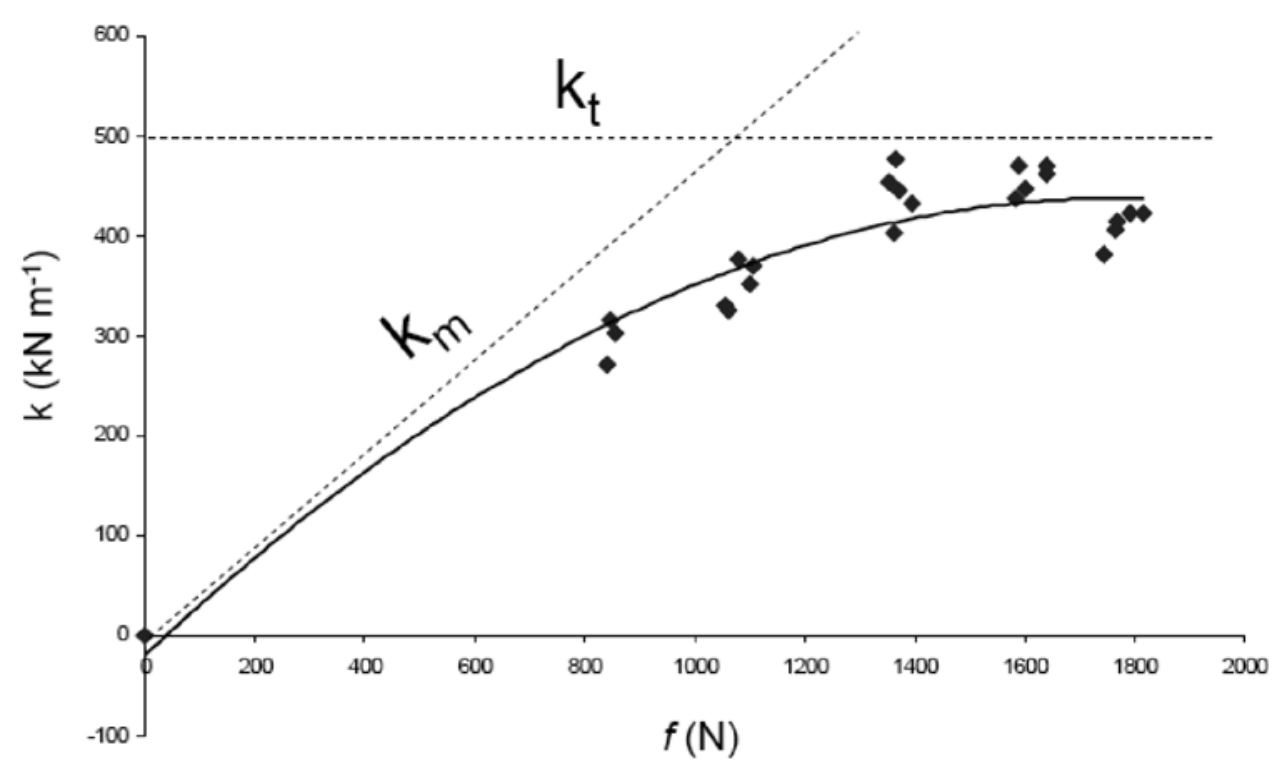

Figure 1 - Representative data from one subject for the determination of muscle $\left(\mathrm{k}_{\mathrm{m}}\right)$ and tendon $\left(\mathrm{k}_{\mathrm{t}}\right)$ stiffness using the free oscillation technique.

The bar acted to counterweight the pull of two linear position transducers (LPTs; Celesco Transducer Products. PT5A-150, Chatsworth, CA, USA), resulting in a zero load. The two LPTs, located anterior and posterior to the subject, were attached to the bar. This resulted in the formation of a triangle that allowed for the calculation of vertical and horizontal displacements through trigonometry involving constants and displacement measurements. ${ }^{27}$ Signals from the two LPTs and the force plate underwent rectangular smoothing with a moving average half-width of 12. The analog signals were collected for every trial at $1000 \mathrm{~Hz}$ using a BNC-2010 interface box with an analog-to-digital card (National Instruments, NI PCI-6014, Austin, TX, USA). Peak force, peak power, peak velocity, and jump height were all measured during the concentric phase of the CMJ. The start of the concentric phase was determined as the point at which the displacement-time curve became positive and was considered finished when the force-time curve became zero. Jump depth was self selected by the subjects to maximize CMJ height. The maximum force recorded from the force-time curve during the concentric phase was reported as the peak force. Concentric peak velocity was measured as the change in bar displacement divided by the change in time in intervals of $0.001 \mathrm{~s}$. Concentric peak power was determined as the force multiplied by the velocity. Jump height was determined to be the difference between the maximum bar displacement and the bar displacement while in the standing position. Furthermore, peak force and peak power were analyzed relative to each subject's body mass. Specifically designed LabVIEW (National Instruments, Version 7.1) programs were used for recording and analyzing the specific variables listed above. 
Strength Measurements. Day 1 also included isometric squat testing. The isometric squat was performed on a force plate (AMTI, BP6001200) located inside a power rack with an attached bar that used pins and hydraulic jacks to establish the desired testing position $\left(140^{\circ} \mathrm{knee}\right.$ angle). Following the test administrator's verbal instruction, subjects pushed with maximal effort as quickly as possible against the immovable bar that was located on their shoulders. Each maximal isometric trial was performed for $3 \mathrm{~s}$, and all subjects were given strong verbal encouragement during each trial. The maximum force recorded from the force-time curve during the 3 -s isometric trial was reported as the peak force (sampling frequency, $1000 \mathrm{~Hz}$, using a BNC-2010 interface box with an analog-to-digital card; National Instruments, NI PCI-6014). Specifically designed LabVIEW (National Instruments, Version 7.1) programs were used for recording and analyzing.

Demographics. On Day 2 subjects came to the Human Performance Laboratory, where anthropometric data were obtained (height, weight, body fat, sit and reach). Subjects arrived in the laboratory without having trained within the last $24 \mathrm{~h}$ and a $>2 \mathrm{~h}$ fast, and were instructed to be euhydrated (avoidance of prior exercise and diuretics). Body composition analysis was performed using a three-site skinfold measurement of the chest, abdomen, and thigh. Body composition was determined using the Siri equation. ${ }^{28}$ Flexibility was assessed using the traditional sit and reach test. Subjects were asked to report their personal-best running times for distances between $400 \mathrm{~m}$ and $10 \mathrm{~km}$ on the track within the last year. Subjects were tested in the preparatory phase before the new track season.

Running Economy. Subjects then performed a discontinuous incremental treadmill test to determine both running economy (RE) and maximal oxygen consumption $\left(\mathrm{VO}_{2} \max \right)$ on Day 2 . For the $\mathrm{RE} / \mathrm{VO}_{2} \max$ test subjects ran on a treadmill (Trackmaster, JAS Fitness Systems) starting at a speed of $187.6 \mathrm{~m} \cdot \mathrm{min}^{-1}$ and $1 \%$ grade. After $3 \mathrm{~min}$, the subjects stepped off the treadmill for approximately $20 \mathrm{~s}$ and a lactate sample was taken. The subjects then got back on the treadmill and the speed was raised in increments of $26.8 \mathrm{~m} \cdot \mathrm{min}^{-1}$ for each 3-min stage. This was continued to $321.6 \mathrm{~m} \cdot \mathrm{min}^{-1}$ or until the subjects reached ventilatory threshold $\left(\mathrm{V}_{\mathrm{E}}\right)$. Once $321.6 \mathrm{~m} \cdot \mathrm{min}^{-1}$ was reached, the treadmill was then increased $0.5 \%$ grade every minute and lactate samples were no longer collected. This protocol was chosen to elicit RE values over a wide range of intensities below the lactate threshold. Speed increases were stopped at $321.6 \mathrm{~m} \cdot \mathrm{min}^{-1}\left(19.35 \mathrm{~km} \cdot \mathrm{h}^{-1}\right.$, or $\left.3: 06 \mathrm{~min} \cdot \mathrm{km}^{-1}\right)$ due to safety concerns at that speed on a treadmill. In addition, beyond this point in the protocol, the majority of subjects had surpassed threshold, in which case RE was no longer measureable, as the anaerobic component is too significant. When subjects reached voluntary exhaustion, a final lactate measurement was taken. Continuous breath-by-breath analysis was performed with a Cosmed b2 $\mathrm{VO}_{2}$ System (Cosmed, Rome, Italy). Breath-by-breath $\mathrm{VO}_{2}$ measurements were averaged during the last minute of each 3-min stage. The RE for each work rate below threshold was then determined by the average oxygen consumption over this 1-min period. Lactate samples were collected using fingertip pricks and heparinized microcapillary tubes. Whole blood samples $(25 \mu \mathrm{L})$ were then immediately placed in microfuge tubes containing $50 \mu \mathrm{L}$ of lysing buffer (Triton X-100 and sodium fluoride in YSI glucose-lactate buffer). Blood samples were analyzed using an YSI 2300 STAT 
Plus glucose and lactate analyzer (Yellow Springs, OH). For the purposes of this test, lactate threshold was defined as an increase of greater than $1.0 \mathrm{mmol}$ in blood lactate with incremental increases in work rate. ${ }^{29}$

Statistical Analysis. Descriptive statistics and Pearson product-moment correlations were performed on all outcome measures (SPSS Version 14.0, SPSS Inc., IL, USA). The significance level was set at $P \leq .05$.

\section{Results}

Subjects in this study were well trained at distances from $1500 \mathrm{~m}$ to the marathon, including collegiate runners and USA Olympic trial qualifiers (Table 1). The average 5000-m time for this group was 15:04 min:s. All subjects successfully achieved $\mathrm{VO}_{2} \max \left(68.3 \pm 4.3 \mathrm{~mL} \cdot \mathrm{kg}^{-1} \cdot \mathrm{min}^{-1}\right)$ as determined by a plateau in oxygen consumption, and an RER of greater than 1.15. As shown in Table 1, there were significant correlations between total years running and performance at distances from $3000 \mathrm{~m}$ to $10,000 \mathrm{~m}$.

Running economy related to performance times $800 \mathrm{~m}$ and longer at stages below lactate threshold (Stages 1 to 6). An example of this strong relationship between $\mathrm{VO}_{2}$ in stage 3 and 3000-m performance is presented in Figure 2. $\mathrm{VO}_{2}$ max did not show significant correlation with any of the performance times (data not shown). However, $\mathrm{VO}_{2} \max$ was related to $\mathrm{VO}_{2}$ at stage $6(r=.89, P<.001)$.

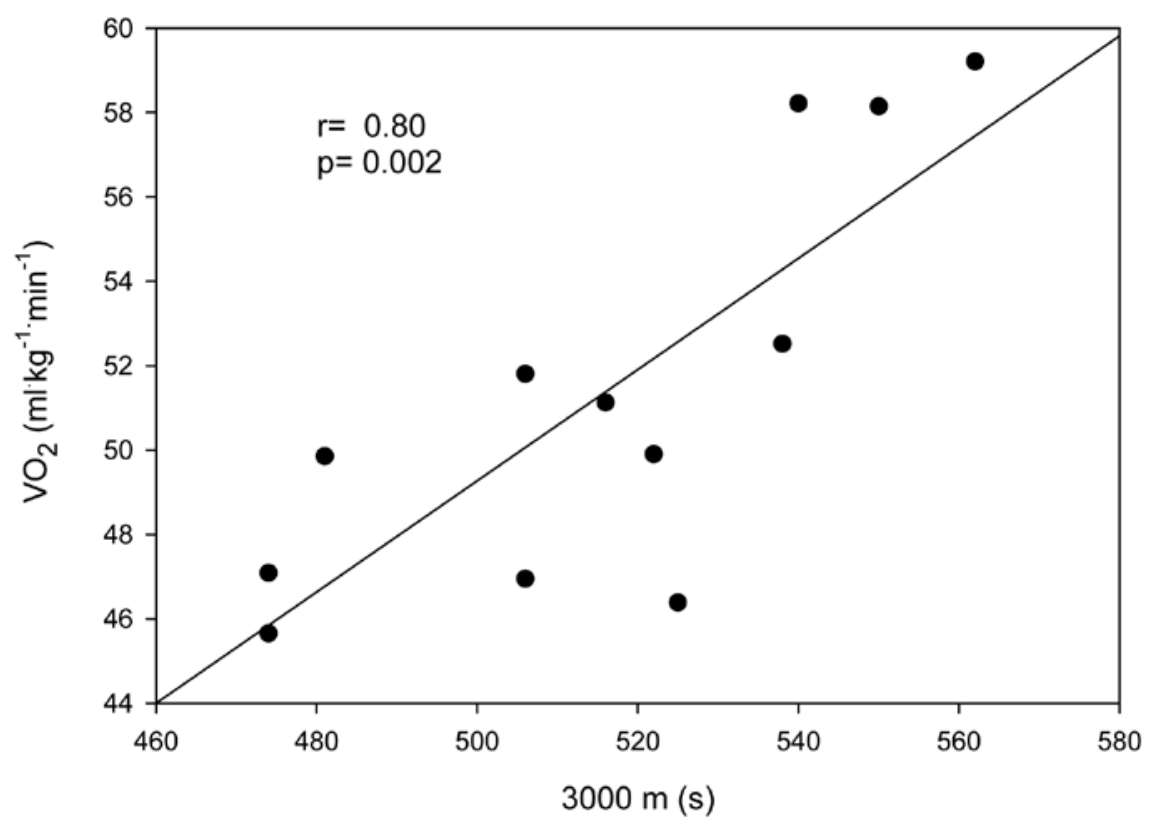

Figure 2 - Relationship between personal-best time in 3000-m run and oxygen consumption $\left(\mathrm{VO}_{2}\right)$ during stage $3\left(241.2 \mathrm{~m} \cdot \mathrm{min}^{-1}\right)$ of treadmill test. 
Table 2 shows mean values for the main outcomes of this study, including muscle $\left(\mathrm{k}_{\mathrm{m}}\right)$ and tendon $\left(\mathrm{k}_{\mathrm{t}}\right)$ stiffness from the passive free oscillation method. There was a statistically significant negative correlation $(\mathrm{r}=-0.69, P=.01)$ observed between $\mathrm{k}_{\mathrm{m}}$ and $\mathrm{VO}_{2}$ during stage $6\left(322 \mathrm{~m} \cdot \mathrm{min}^{-1}\right.$, $1 \%$ incline; Figure $\left.3 \mathrm{~A}\right)$. No significant correlations were observed between $\mathrm{k}_{\mathrm{t}}$ and $\mathrm{VO}_{2}$ at any of the subthreshold stages. Sit and reach scores also did not relate to $\mathrm{VO}_{2}$ at any of the subthreshold stages. Mean values for CMJs and SJs are provided in Table 2. There were no statistically significant correlations between either the CMJ or the SJ variables with $\mathrm{k}_{\mathrm{m}}$ or $\mathrm{k}_{\mathrm{t}}$. There were, however, statistically significant correlations between CMJ peak force and $\mathrm{VO}_{2}$ at several subthreshold work rates (Figure 3B). There were no statistically significant correlations between peak isometric squat force with $\mathrm{k}_{\mathrm{m}}$ and $\mathrm{k}_{\mathrm{t}}$. There was a significant correlation between peak isometric squat and $\mathrm{VO}_{2}$ at stage $4(r=.57, P=.05)$, and a trend for isometric peak force during plantar flexion (Iso PF) and $\mathrm{VO}_{2}$ at stage $5(r=.53, P=.07)$.

\section{Table 2 Subject population outcome measures}

\begin{tabular}{lcc}
\hline Variable $\mathbf{N}=\mathbf{1 2}$ & Mean \pm SD & Range \\
\hline $\mathrm{SJ}$ (watts) & $3093 \pm 638$ & $2375-4750$ \\
$\mathrm{CMJ}$ (watts) & $3321 \pm 757$ & $2554-5200$ \\
Iso. Squat (newtons) & $2373 \pm 362$ & $1745-2956$ \\
Iso. PF (newtons) & $1596 \pm 274$ & $1088-2119$ \\
$\mathrm{k}_{\mathrm{m}}\left(\mathrm{kN} \cdot \mathrm{m}^{-1}\right)$ & $761.8 \pm 275$ & $377-1373$ \\
$\mathrm{k}_{\mathrm{t}}\left(\mathrm{kN} \cdot \mathrm{m}^{-1}\right)$ & $287.9 \pm 97.9$ & $127.6-433$ \\
$\mathrm{k}_{\mathrm{m}} / \mathrm{kg}$ & $11.75 \pm 5.1$ & $5.9-25.6$ \\
$\mathrm{k}_{\mathrm{t}} / \mathrm{kg}$ & $4.42 \pm 1.7$ & $2.0-7.1$ \\
\hline
\end{tabular}

Note. Values are mean $\pm \mathrm{SD} . \mathrm{SJ}=$ static jump, $\mathrm{CMJ}=$ countermovement jump, Iso. Squat $=$ isometric squat force, Iso. $\mathrm{PF}=$ isometric peak force during plantar flexion of triceps surae, $\mathrm{k}_{\mathrm{m}}=$ muscle stiffness of triceps surae, and $\mathrm{k}_{\mathrm{t}}=$ tendon stiffness of triceps surae.

\section{Discussion}

The current study demonstrated that muscle stiffness as measured in this investigation is significantly related to $\mathrm{RE}$ at a speed that approximates endurance competition. This is a unique finding not previously reported in the literature. Muscle and tendon are two springs in series, in the translation of energy expenditure to ground force during running more energy is stored in the more compliant spring. As stiffness increases, less muscle activation is required, and therefore energy expenditure is spared. Since muscle is the more compliant of the two springs, it is conducive to its relationship with RE since the triceps surae unit would be dependent on its most compliant spring. Kubo et $\mathrm{al}^{30}$ measured the viscoelastic properties (stiffness and hysteresis) of tendon at a fixed ankle and knee joint using ultrasonography. They found that these properties related to the stretch shortening cycle during plantar flexion exercise. 

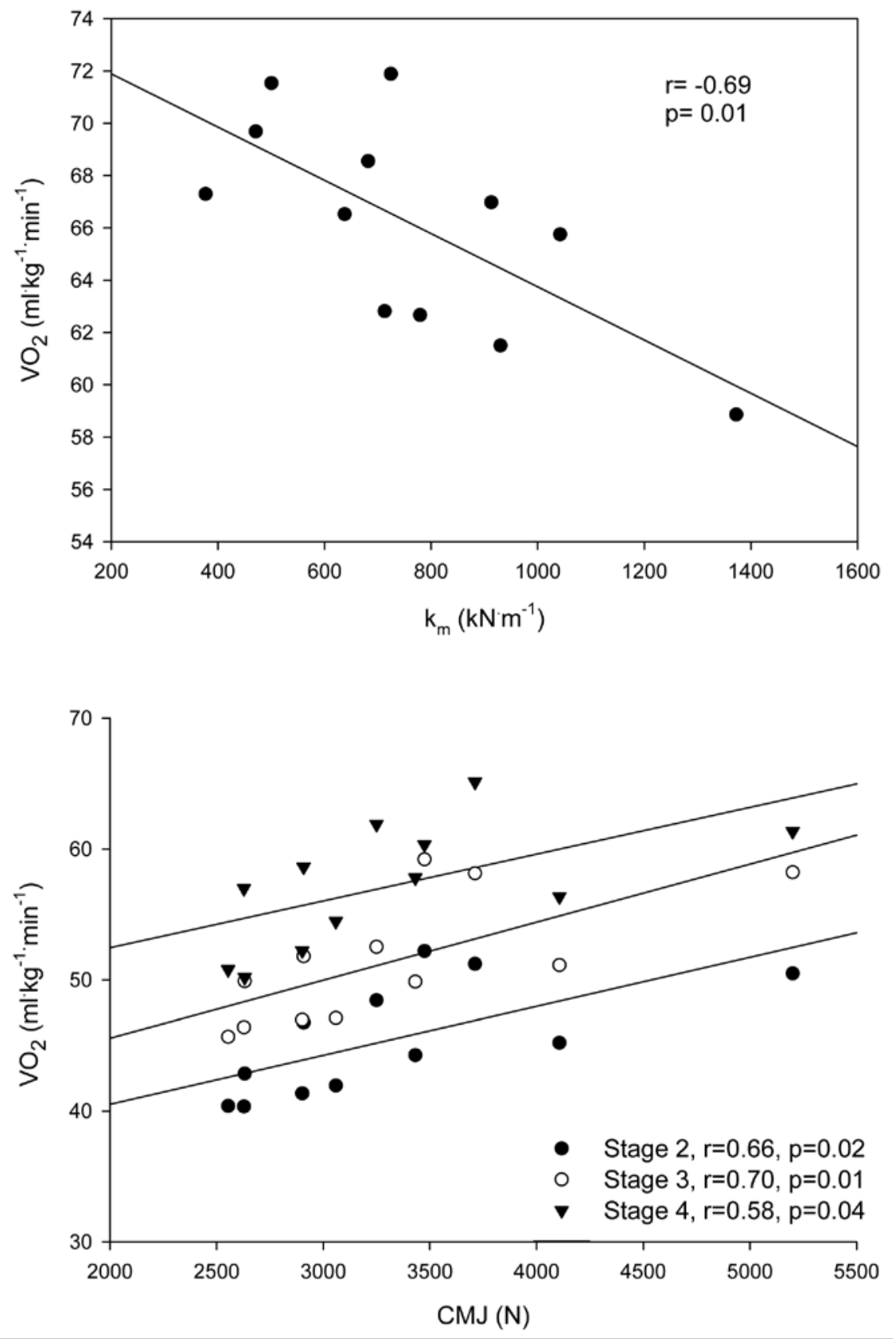

Figure 3 - Top panel: Relationship between oxygen consumption $\left(\mathrm{VO}_{2}\right)$ and $\mathrm{k}_{\mathrm{m}}$ during Stage $6\left(321.6 \mathrm{~m} \cdot \mathrm{min}^{-1}\right)$ of the treadmill test. Bottom panel: Correlations between countermovement jump (CMJ) peak force and oxygen consumption $\left(\mathrm{VO}_{2}\right)$ at Stages 2 (214.4 $\left.\mathrm{m} \cdot \mathrm{min}^{-1}\right), 3\left(241.2 \mathrm{~m} \cdot \mathrm{min}^{-1}\right)$, and $4\left(268 \mathrm{~m} \cdot \mathrm{min}^{-1}\right)$. 
Indeed, previous evidence has shown that triceps surae tendon stiffness related to RE in a group of runners. ${ }^{31}$ The differences between our study and those of Kubo and Arampatzis are likely methodological. Currently there is no standard method to measure muscle and tendon stiffness separately. Arampatzis et $\mathrm{al}^{31}$ used ultrasonography to measure tendon stiffness at eleven different ankle and knee joint angles. We estimated muscle and tendon stiffness at one ankle and knee joint angle. We chose this muscle and tendon stiffness technique because of its previous use $\mathrm{e}^{10,24-26}$ and established validity and reliability. ${ }^{26}$ However, it is not without limitations. The muscle stiffness values calculated are passive stiffness values and muscle stiffness during exercise could be altered by increasing muscle activation. Our technique determines stiffness at one joint angle, which is not truly the case during running. It also remains unknown how changes in muscle activation and ankle angle would affect energy utilization and thus RE. It is possible that the method for tendon stiffness employed in the current study is more representative of series stiffness of the foot, ankle and plantar flexor muscles and not tendon stiffness independent of the whole system. Indeed what may be considered muscle stiffness utilizing the free oscillation technique, could be gastrocnemius tendon stiffness using ultrasonography. ${ }^{16,31,32}$ In fact no study to date has convincingly isolated muscle stiffness in vivo. Investigations on myosin heavy chain and titin isofoms ${ }^{19}$ may be the most applicable, but they do not come without their own limitations. It should also be noted that the stiffness measures in the current study were obtained during a $90^{\circ}$ bent knee joint procedure, whereas running involves a more straight leg pattern. Despite these limitations, this is the first time the free oscillation technique was used to measure muscle and tendon stiffness of the triceps surae muscle group in well-trained runners. The numbers we obtained in our 12 well-trained runners for $\mathrm{k}_{\mathrm{m}}$ and $\mathrm{k}_{\mathrm{t}}$ (762 and $288 \mathrm{kN} \cdot \mathrm{m}^{-1}$ respectively) were similar to those of Fukashiro et $\mathrm{al}^{24}$ utilizing six untrained men and women $\left(611\right.$ and $\left.364 \mathrm{kN} \cdot \mathrm{m}^{-1}\right)$. Whereas this method has been used to explain differences in drop jump performance, ${ }^{33}$ racial differences, ${ }^{25}$ and response to plyometric training, ${ }^{10}$ this is the first study to indicate that the greater the muscle stiffness, the greater the running economy (reduced $\mathrm{VO}_{2}$ ) in well-trained runners.

The conversion of energy to motion involves recoil of some elastic energy in muscle and tendon. A "stiffer" muscle or tendon thus is better at transferring energy economically or without the need for additional oxygen consumption. ${ }^{10,20-23}$ Similar to other studies, ${ }^{2,3}$ it was demonstrated that RE related strongly to performance times at distances greater than $800 \mathrm{~m}$. Interestingly, at the stage where muscle stiffness related to $\mathrm{RE}, \mathrm{VO}_{2}$ max was also related to $\mathrm{RE}$. This suggests that the runners with the highest $\mathrm{VO}_{2} \max$ had the poorest running economy at higher intensities. This is strengthened by the result that $\mathrm{VO}_{2}$ max did not relate to performance times at any distance between $800 \mathrm{~m}$ and $10 \mathrm{~km}$. Similar results have been reported in cyclists, where cycling economy negatively correlated with $\mathrm{VO}_{2}$ max. ${ }^{34}$ These data contribute to the understanding that improvements in running economy may be more important to running performance than changes in $\mathrm{VO}_{2} \max$.

The range of passive stiffness values found in this pool of well-trained runners may be explained by genetic individual variability or by differences in athletic or training history. Spurrs et $\mathrm{al}^{10}$ used a similar method to determine triceps surae stiffness, which they grouped into a "musculotendinous stiffness" (MTS) measurement. Following $6 \mathrm{wk}$ of plyometric training, subjects increased MTS and showed 
improvements in $\mathrm{RE}$ and performance despite no changes in $\mathrm{VO}_{2}$ max or lactate threshold. This longitudinal study is important in demonstrating the trainability of the triceps surae musculotendinous unit in runners. However, it is unclear whether the training had a larger impact on the muscle or tendon properties. In addition, although increases in MTS were correlated with improvements in RE, they did not correlate with changes in 3-km performance times. In addition, the subject population was different than the one in the current study. Mean 3-km times were more than $100 \mathrm{~s}$ faster in the current study as compared with the Spurrs et $\mathrm{al}^{10}$ experimental group. It remains to be seen whether muscle and tendon stiffness is trainable in already well-trained runners.

Muscle and tendon stiffness has been measured in other modalities as well. Previous reports have demonstrated that strength training increases muscle and tendon stiffness and power. ${ }^{16,17,32}$ Both power and strength training may affect changes in different parts of the muscle tendon unit. Comparison between the current study and previous reports of muscle-tendon stiffness become blurred as techniques used in this determination have varied. Burgess et $\mathrm{al}^{16}$ used ultrasonography to determine medial gastrocnemius tendon stiffness following plyometrics and isometric training. Both types of training resulted in increases in tendon stiffness and jump height. It remains unclear whether gastrocnemius tendon stiffness would be grouped in the muscle or tendon stiffness measurement during the free oscillation technique of the triceps surae used in the current study. Kubo et a ${ }^{17}$ used ultrasonic techniques to measure achilles tendon stiffness and a drop jump to determine joint stiffness. They found that plyometric training (hopping and drop jump) increased joint stiffness but not tendon stiffness, whereas tendon but not joint stiffness increased following weight training (80\% 1RM). This same research group showed increases in vastus lateralis "tendon-aponeurosis" complex following isometric squat training. ${ }^{35}$ Although these investigations were not related to running economy, there is growing evidence that strength and power training may be a method to increase muscle and tendon stiffness. Numerous studies have demonstrated a clear link between strength training and positive changes in RE and performance. . $^{5,-12}$

Factors that contribute to the musculotendinous unit stiffness are difficult to determine. Flexibility was previously demonstrated to negatively relate to running economy. ${ }^{36-38}$ However, not all studies show this relationship, ${ }^{39,40}$ in fact, we did not show a correlation between sit and reach and running economy in the current study. This may have been because of our relatively small pool of well-trained runners. Muscle fiber composition, myosin heavy chain (MHC) and titin isoform have also been considered important factors in RE. ${ }^{19}$ This study found that MHC II isoform related negatively with energy expenditure at high running speeds in middle distance runners, although this may have been a function of the subject population or running speed, since others found a positive relationship between oxygen consumption and fast twitch fibers at slower running speeds. ${ }^{41}$ Of course, we did not measure muscle fiber type in the current study, but we did find that $\mathrm{CMJ}$ and peak isometric squat related positively with oxygen consumption below threshold. This suggests the strongest runners had the worst RE. Despite this, we did not find CMJ and isometric squat relationships with $\mathrm{k}_{\mathrm{m}}$ or $\mathrm{k}_{\mathrm{t}}$. The impact of these results is not currently apparent. It is not simply a function of athlete size, as body weight and lean body mass did not relate to RE or $\mathrm{k}_{\mathrm{m}}, \mathrm{k}_{\mathrm{t}}$ or $\mathrm{k}_{\mathrm{m}}$ and $\mathrm{k}_{\mathrm{t}}$ normalized to body weight. Certainly the complexity of RE is not possibly explained by a 
sole measurable component. The importance of the contribution of all the potential factors relating to RE such as muscle and tendon stiffness in series, joint angles, $\mathrm{VO}_{2}$ max, muscle structure and fiber type have yet to be determined.

\section{Practical Applications}

Running economy relates strongly with running performance in events lasting longer than just a few minutes. As we demonstrate here, RE may be in part explained by muscle stiffness as measured by the free oscillation technique. A limitation of the current study is that it was not longitudinal in nature. It was beyond the scope of this research to determine how muscle stiffness is improved. While it is thought that muscle stiffness contributes positively to RE, it remains to be seen how this is best accomplished. Previous reports have shown a variety of training approaches that can improve running economy from interval, strength and plyometric training, altitude training and hill running. ${ }^{4-10}$ While it is known that strength and power training increase RE, it is still unclear as to the mechanism by which this is accomplished. It also remains to be determined the trainability of muscle stiffness across varying levels of fitness. Whether various methods of training improve RE through improvement of muscle and tendon stiffness may not matter to runners and coaches, and has yet to be shown convincingly by researchers. However, the improvement in running performance through enhanced RE is certainly a worthwhile goal.

\section{Conclusions}

We have demonstrated that in a well-trained group of runners, RE related strongly to performance, and that there is a relationship between muscle stiffness and RE. The results of this study suggest that muscle stiffness is an important component contributing to running economy.

\section{Acknowledgments}

The authors would like to thank the subjects for their participation.

\section{References}

1. Saunders PU, Pyne DB, Telford RD, Hawley JA. Reliability and variability of running economy in elite distance runners. Med Sci Sports Exerc. 2004;36:1972-1976.

2. Conley DL, Krahenbuhl GS. Running economy and distance running performance of highly trained athletes. Med Sci Sports Exerc. 1980;12:357-360.

3. Morgan DW, Baldini FD, Martin PE, Kohrt WM. Ten kilometer performance and predicted velocity at $\mathrm{VO}_{2 \max }$ among well-trained male runners. Med Sci Sports Exerc. 1989;21:78-83.

4. Denadai BS, Ortiz MJ, Greco CC, de Mello MT. Interval training at $95 \%$ and $100 \%$ of the velocity at $\mathrm{VO} 2$ max: effects on aerobic physiological indexes and running performance. Appl Physiol Nutr Metab. 2006;31:737-743.

5. Paavolainen L, Hakkinen K, Hamalainen I, Nummela A, Rusko H. Explosive-strength training improves $5-\mathrm{km}$ running time by improving running economy and muscle power. J Appl Physiol. 1999;86:1527-1533. 
6. Saunders PU, Telford RD, Pyne DB, Hahn AG, Gore CJ. Improved running economy and increased hemoglobin mass in elite runners after extended moderate altitude exposure. J Sci Med Sport. 2009;12:67-72.

7. Guglielmo LG, Greco CC, Denadai BS. Effects of strength training on running economy. Int J Sports Med. 2009;30:27-32.

8. Storen O, Helgerud J, Stoa EM, Hoff J. Maximal strength training improves running economy in distance runners. Med Sci Sports Exerc. 2008;40:1087-1092.

9. Yamamoto LM, Lopez RM, Klau JF, et al. The effects of resistance training on endurance distance running performance among highly trained runners: a systematic review. J Strength Cond Res. 2008;22:2036-2044.

10. Spurrs RW, Murphy AJ, Watsford ML. The effect of plyometric training on distance running performance. Eur J Appl Physiol. 2003;89:1-7.

11. Millet GP, Jaouen B, Borrani F, Candau R. Effects of concurrent endurance and strength training on running economy and. $\mathrm{VO}(2)$ kinetics. Med Sci Sports Exerc. 2002;34:1351-1359.

12. Turner AM, Owings M, Schwane JA. Improvement in running economy after 6 weeks of plyometric training. J Strength Cond Res. 2003;17:60-67.

13. Saunders PU, Pyne DB, Telford RD, Hawley JA. Factors affecting running economy in trained distance runners. Sports Med. 2004;34:465-485.

14. Saunders PU, Telford RD, Pyne DB, et al. Short-term plyometric training improves running economy in highly trained middle and long distance runners. J Strength Cond Res. 2006;20:947-954.

15. Wilson GJ, Wood GA, Elliott BC. Optimal stiffness of series elastic component in a stretch-shorten cycle activity. J Appl Physiol. 1991;70:825-833.

16. Burgess KE, Connick MJ, Graham-Smith P, Pearson SJ. Plyometric vs. isometric training influences on tendon properties and muscle output. J Strength Cond Res. 2007;21:986-989.

17. Kubo K, Morimoto M, Komuro T, et al. Effects of plyometric and weight training on muscle-tendon complex and jump performance. Med Sci Sports Exerc. 2007;39:18011810.

18. Kubo K, Ohgo K, Takeishi R, et al. Effects of isometric training at different knee angles on the muscle-tendon complex in vivo. Scand J Med Sci Sports. 2006;16:159-167.

19. Kyrolainen H, Kivela R, Koskinen S, et al. Interrelationships between muscle structure, muscle strength, and running economy. Med Sci Sports Exerc. 2003;35:45-49.

20. Cavagna GA, Kaneko M. Mechanical work and efficiency in level walking and running. J Physiol. 1977;268:467-481.

21. Dalleau G, Belli A, Bourdin M, Lacour JR. The spring-mass model and the energy cost of treadmill running. Eur J Appl Physiol Occup Physiol. 1998;77:257-263.

22. Lichtwark GA, Wilson AM. Optimal muscle fascicle length and tendon stiffness for maximising gastrocnemius efficiency during human walking and running. J Theor Biol. 2008;252:662-673.

23. Bojsen-Moller J, Magnusson SP, Rasmussen LR, Kjaer M, Aagaard P. Muscle performance during maximal isometric and dynamic contractions is influenced by the stiffness of the tendinous structures. J Appl Physiol. 2005;99:986-994.

24. Fukashiro $S$, Noda $M$, Shibayama A. In vivo determination of muscle viscoelasticity in the human leg. Acta Physiol Scand. 2001;172:241-248.

25. Fukashiro S, Abe T, Shibayama A, Brechue WF. Comparison of viscoelastic characteristics in triceps surae between Black and White athletes. Acta Physiol Scand. 2002;175:183-187.

26. Walshe AD, Wilson GJ, Murphy AJ. The validity and reliability of a test of lower body musculotendinous stiffness. Eur J Appl Physiol Occup Physiol. 1996;73:332-339. 
27. Cormie P, McBride JM, McCaulley GO. Power-time, force-time, and velocity-time curve analysis of the countermovement jump: impact of training. J Strength Cond Res. 2009;23:177-186.

28. Siri WE. Body composition from fluid spaces and density: analysis of methods. 1961. Nutrition 1993;9:480-491; discussion 480, 492.

29. Coyle EF, Martin WH, Ehsani AA, et al. Blood lactate threshold in some well-trained ischemic heart disease patients. J Appl Physiol. 1983;54:18-23.

30. Kubo K, Kanehisa H, Fukunaga T. Effects of viscoelastic properties of tendon structures on stretch - shortening cycle exercise in vivo. J Sports Sci. 2005;23:851-860.

31. Arampatzis A, De Monte G, Karamanidis K, et al. Influence of the muscle-tendon unit's mechanical and morphological properties on running economy. $J$ Exp Biol. 2006;209:3345-3357.

32. Reeves ND, Narici MV, Maganaris CN. Strength training alters the viscoelastic properties of tendons in elderly humans. Muscle Nerve. 2003;28:74-81.

33. Walshe AD, Wilson GJ. The influence of musculotendinous stiffness on drop jump performance. Can J Appl Physiol. 1997;22:117-132.

34. Lucia A, Hoyos J, Perez M, Santalla A, Chicharro JL. Inverse relationship between $\mathrm{VO}_{2 \max }$ and economy/efficiency in world-class cyclists. Med Sci Sports Exerc. 2002;34:2079-2084.

35. Kubo K, Yata H, Kanehisa H, Fukunaga T. Effects of isometric squat training on the tendon stiffness and jump performance. Eur J Appl Physiol. 2006;96:305-314.

36. Craib MW, Mitchell VA, Fields KB, et al. The association between flexibility and running economy in sub-elite male distance runners. Med Sci Sports Exerc. 1996;28:737-743.

37. Jones AM. Running economy is negatively related to sit-and-reach test performance in international-standard distance runners. Int J Sports Med. 2002;23:40-43.

38. Trehearn TL, Buresh RJ. Sit-and-reach flexibility and running economy of men and women collegiate distance runners. J Strength Cond Res. 2009;23:158-162.

39. Beaudoin CM, Whatley Blum J. Flexibility and running economy in female collegiate track athletes. J Sports Med Phys Fitness. 2005;45:295-300.

40. Nelson AG, Kokkonen J, Eldredge C, Cornwell A, Glickman-Weiss E. Chronic stretching and running economy. Scand J Med Sci Sports. 2001;11:260-265.

41. Bosco C, Montanari G, Ribacchi R, et al. Relationship between the efficiency of muscular work during jumping and the energetics of running. Eur J Appl Physiol Occup Physiol. 1987;56:138-143. 